NBER WORKING PAPER SERIES

NUTRITION LABELS AND OBESITY

Jayachandran N. Variyam

John Cawley

Working Paper 11956

http://www.nber.org/papers/w11956

\author{
NATIONAL BUREAU OF ECONOMIC RESEARCH \\ 1050 Massachusetts Avenue \\ Cambridge, MA 02138 \\ January 2006
}

Contact information: Jayachandran N. Variyam, Economic Research Service, USDA 1800 M Street, NW, Room N2117, Washington, DC 20036-5831. E-Mail: jvariyam@ers.usda.gov. The views expressed in this paper are those of the authors and do not reflect the views of the Economic Research Service or the USDA. We thank participants at the Association for Public Policy and Management Fall Conference for their helpful comments. The views expressed herein are those of the author(s) and do not necessarily reflect the views of the National Bureau of Economic Research.

(C2006 by Jayachandran N. Variyam and John Cawley. All rights reserved. Short sections of text, not to exceed two paragraphs, may be quoted without explicit permission provided that full credit, including () notice, is given to the source. 
Nutrition Labels and Obesity

Jayachandran N. Variyam and John Cawley

NBER Working Paper No. 11956

January 2006

JEL No. I18

\begin{abstract}
$\underline{\text { ABSTRACT }}$
The Nutrition Labeling and Education Act (NLEA) imposed significant changes in the information about calories and nutrients that manufacturers of packaged foods must provide to consumers. This paper tests whether the release of this information impacted body weight and obesity among American adults. We estimate the effect of the new label using a difference-in-differences method. We compare the change before and after the implementation of NLEA in body weight among those who use labels when food shopping to that among those who do not use labels. In National Health Interview Survey data we find, among non-Hispanic white women, that the implementation of the new labels was associated with a decrease in body weight and the probability of obesity. Using NLEA regulatory impact analysis benchmarks, we estimate that the total monetary benefit of this decrease in body weight was $\$ 63$ to $\$ 166$ billion over a 20 -year period, far in excess of the costs of the NLEA.

Jayachandran N. Variyam Economic Research Service USDA 1800 M Street, NW, Room N2117

Washington, DC 20036-5831

jvariyam@ers.usda.gov

John Cawley 124 MVR Hall Department of Policy Analysis and Management Cornell University Ithaca, NY 14853 and NBER jhc38@cornell.edu
\end{abstract}




\section{Nutrition Labels and Obesity}

The Nutrition Labeling and Education Act (NLEA) of 1990 represented the first comprehensive overhaul of the nation's food labeling laws in over half a century. ${ }^{1}$ Prior to the NLEA, food labeling was voluntary and labels were required only for products containing added nutrients or that made nutrition claims. The NLEA, which took effect in 1994, made labeling mandatory for most processed foods. It requires manufacturers of packaged foods to display the Nutrition Facts panel, which lists in a standardized format the amount of key macronutrients, vitamins, and minerals contained per serving. The NLEA also requires manufacturers to use specified serving sizes within product categories, declare nutrients as a percent of the recommended Daily Value, and use approved health and nutrient content claims (Food and Drug Administration, 1999).

This paper examines whether the nutrition labeling changes introduced by the NLEA have impacted body weight and obesity among American adults. The NLEA was motivated by a growing body of scientific evidence linking dietary habits with obesity and chronic diseases such as cardiovascular disease, diabetes and some types of cancer. Two back-to-back reports documenting such evidence - the 1988 Surgeon General's Report on Nutrition and Health, and the 1989 National Research Council's Diet and Health: Implications for Reducing Chronic Disease Risk - provided impetus to the legislation. In 1990, the year the NLEA was enacted, voluntary labeling rules in existence were deemed seriously outdated with no nutrition information appearing on at least 40 percent of packaged foods and the available information "incomplete and misfocused," according to a study commissioned by the Food and Drug Administration (FDA) and the Food Safety Inspection Service (FSIS) (Porter and Earl, 1990). The new labeling regulations were expected to help consumers choose more healthful diets 
through improved access to credible nutrition information (Kurtzweil, 1993, 1994). FDA's estimates of the health benefit from dietary changes triggered by the new labeling regulations ranged from $\$ 4.4$ to $\$ 26.5$ billion gained over 20 years. The total cost of NLEA implementation, including administrative and compliance costs, was projected to be between $\$ 1.4$ billion and \$2.3 billion (Food and Drug Administration, 1993).

The rising prevalence of obesity in the United States, however, has focused attention on the effectiveness of the NLEA labeling rules in improving health outcomes. The Calorie Counts report prepared by the FDA's Obesity Working Group in 2004 notes that "Despite reports of a positive correlation between label use and certain positive dietary characteristics, the trend toward obesity has accelerated over the past decade." Although obesity among Americans began to rise noticeably in the 1980 s, its increase has continued unabated even after food labels were mandated by the NLEA. Data from the National Health Interview Survey (NHIS) suggests that adult obesity has increased continuously since the NLEA enforcement, rising from 18\% in 1995 to $23 \%$ in 2003 . Other health surveys such as the National Health and Nutrition Examination Survey (NHANES) confirm this trend (Flegal et al., 2002). Aggregate adult medical expenditure attributable to obesity in 1998 has been estimated to range between $\$ 26.8$ and $\$ 47.5$ billion (Finkelstein, Fiebelkorn, and Wang, 2003).

The upward trend in aggregate obesity prevalence by itself, however, does not imply that the NLEA has been ineffective in stemming obesity. What exactly has been the effect of the mandatory nutrition labels introduced by the NLEA on the body weight and obesity among Americans? Surprisingly, despite being of considerable public policy interest, there has been 
little empirical research on this question. The interest in better understanding the effect of food labeling on obesity and other dietary outcomes is not confined to the U.S. The World Health Organization's Global strategy on diet, physical activity and health suggests nutrition labeling as a way to meet the consumers' need for accurate, standardized and comprehensible information in order to make healthy food choices. A growing number of countries are implementing mandatory nutrition labeling regulations to achieve the public health goal of reducing obesity and preventing chronic disease (Hawkes, 2004).

In the next section, we review the existing literature on the effect of the NLEA and the Nutrition Facts panel information on different consumer outcomes. Section 3 describes our empirical strategy for estimating the effect of the new label on body weight and the data and specific measures that we use to implement this strategy. Section 4 reports our main findings and results of sensitivity analysis to check the robustness of the estimates. In section 5, we calculate the dollar value of the BMI reductions due to the NLEA and conclude with a discussion of the implications of our finding for mandatory nutrition labeling policy in the U.S. and other countries.

\section{Previous Research}

Although NLEA has been in effect for over a decade, relatively few studies have explored its effect on dietary intakes and, to the best of our knowledge, none has studied its effect on obesity. $^{2}$ A few studies in the nutrition literature have examined correlations or regressionadjusted associations between label use and dietary intakes and diet quality, and reported beneficial effects associated with label use (Kreuter et al., 1997; Neuhouser, Kristal, and 
Patterson, 1999; Perez-Escamilla and Haldeman, 2002). A study that specified label use as an endogenous switching variable found significant beneficial effects for label use on the intakes of fats, cholesterol, sodium, and fiber (Kim, Nayga, and Capps, 2000). Their label use equation was identified by excluding a potentially endogenous variable — whether an individual considers nutrition an important factor when shopping for food—from the intake equations. Kristal et al. (2001) used data collected from two rounds of a Washington State consumer sample in 1995-96 and 1997-98 to predict the impact of label use on intake of fat and fruits and vegetables and found that use of food labels was associated with reduced fat intake. Despite the longitudinal data, the study did not control for unobserved effects that may have influenced both label use and intakes.

Moorman (1996) studied the effect of the NLEA on consumer comprehension and processing of label information using a longitudinal quasi-experimental design. The study gathered label use data from samples of consumers in October $1993(\mathrm{~N}=554)$ and October $1994(\mathrm{~N}=558)$ —eight months before and five months after the May 1994 implementation of the NLEA. Findings indicated that consumers acquired and comprehended more nutrition information following the introduction of the new labels. Relatively more information was acquired about nutritionally unhealthy products compared with healthy products, suggesting that labels may have a public health benefit. These findings are supported by another study with a similar pre- and post-NLEA design (Balasubramanian and Cole, 2002). NLEA changed consumer attention to negative nutritional attributes (such as fat and sodium, of which less is better) and more motivated consumers registered greater label search intensity in the post-NLEA period compared with the pre-NLEA period. 
Overall, research on the relationship between food label use, particularly as implemented under the NLEA, and dietary and health outcomes remains limited (Institute of Medicine, 2003; Pappalardo, 2001). This is the case even though there has been a spirited debate about the NLEA's effectiveness, which has only sharpened in light of the obesity epidemic (Philipson, 2005).

\section{Empirical Strategy and Data}

\section{Estimating the label effect}

The main innovation in food labeling introduced by the NLEA is the Nutrition Facts panel, which presents essential nutrition information in a standardized, easily comprehensible format. Thus, much of the benefit from the NLEA was expected to occur when consumers read the labels and use the information in their food selection (Kurtzweil, 1994; Zarkin et. al., 1993). Labels existed before the NLEA under the voluntary labeling rules established by the FDA in 1975, but they were not on all packaged foods and were not standardized. We exploit this fact and estimate the effect of the new label on body weight by comparing the change in body weight of individuals who used labels in their food selection in periods before and after the NLEA's implementation with the change in the body weight over the same period of those who did not use the labels.

Suppose $\overline{W G T}$ denotes the mean of the body weight outcome variable, and that $u$ and $n$ indicate label user/nonuser status, and that $a$ and $b$ indicate periods after and before NLEA. Using the difference-in-differences (DD) strategy, the label effect $\delta_{l}$ can be estimated from the equation 


$$
\delta_{l}=\left(\overline{W G T}_{u}^{a}-\overline{W G T}_{u}^{b}\right)-\left(\overline{W G T}_{n}^{a}-\overline{W G T}_{n}^{b}\right) .
$$

Ideally we would have data from a randomized experiment in which subjects were randomly assigned to either the label user $(u)$ or the label nonuser $(n)$ groups. Since our data is nonexperimental, selection bias is a potential problem. That is, nonusers may have had different changes in weight than label users over the period we examine for reasons that had nothing to do with the NLEA. To address this, we control for observable correlates of weight in the following regression:

(2) $\quad W G T_{i}=\beta_{0}+\beta_{1} L A B E L_{i}+\beta_{2} N L E A_{i}+\delta_{l} L A B E L_{i} * N L E A_{i}+\beta_{3} X_{i}+\beta_{4} X_{i}^{*} N L E A_{i}+\varepsilon_{i}$. The dependent variable $W G T_{i}$ represents the weight outcome of the ith individual. $L A B E L_{i}$ is an indicator variable that equals 1 if the individual is a label user and 0 if the individual is a label nonuser. $N L E A_{i}$ is an indicator variable that equals 1 for the post-NLEA years and 0 for preNLEA years. The coefficient $\delta_{l}$ for the $L A B E L_{i}{ }^{*} N L E A_{i}$ interaction variable is the differencein-differences (DD) estimate of the effect of the NLEA. The vector of characteristics $X_{i}$ controls for differences in weight outcomes due to other influences, and the interaction terms $X_{i}{ }^{*} N L E A_{i}$ control for variation in the impact of characteristics across the pre/post-NLEA periods. These two sets of regressors $\left(X_{i}\right.$ and $\left.X_{i}{ }^{*} N L E A_{i}\right)$ are included to address the fact that our data are non-experimental. We assume that our treatment group indicator $L A B E L_{i}$ is uncorrelated with the residual weight $\varepsilon_{i}$ after we control for the observable correlates of weight $X_{i}$ and $X_{i}{ }^{*} N L E A_{i}$. As we explain in the data section, these observable correlates of weight include age, marital status, education, income, family size, urban, region, smoking status, self-reported health, dieting behavior, and other information about diet. 


\section{Data Source}

We implement this empirical strategy using data from the National Health Interview Survey (NHIS). The NHIS is a multipurpose survey of the U.S. civilian noninstitutionalized population fielded annually since 1958. A probability sample of households is interviewed weekly by trained Census interviewers to obtain information about the health and sociodemographic characteristics of the household members. Additionally, supplementary questionnaires are administered periodically to gather detailed information on specific health topics of interest. Approximately 36,000 to 47,000 households, including 92,000 to 125,000 persons are interviewed each year. NHIS is the principal source of health statistics in the U.S. (National Center for Health Statistics, 2000).

The NHIS uses a multistage probabilistic sampling design to represent the U.S. civilian noninstitutionalized population. Each person in the covered population has a known nonzero probability of selection. Sample weights provided in the NHIS data files reflect these probabilities of selection, along with adjustments for nonresponse and post-stratification. The empirical analyses in this study were undertaken taking into account the sample weights and the complex sample survey design. All estimates were generated using the SUDAAN software (Research Triangle Institute, 2005).

\section{Nutrition Label Use}

Our primary covariate of interest is the label use behavior of consumers over a time period that spans the NLEA implementation. During the 1991, 1993, 1995, and 1998 rounds of the NHIS, supplementary modules administered to adult respondents aged 18 and older included an 
identically worded question on food label use: "When you buy a food item for the first time, how often would you say you read the NUTRITIONAL INFORMATION about calories, fat, and cholesterol sometimes listed on the label—would you say always, often, sometimes, rarely, or never?" As noted earlier, currently the nutritional information listing the amount of calories, fat, and other nutrients is found on the Nutrition Facts panel. Under the voluntary labeling regime that existed prior to the NLEA, up to $60 \%$ of packaged foods had some form of labeling listing such nutrients (Porter and Earl, 1990). The NHIS label use question is thus general enough to capture label use before and after the NLEA. For our analysis, we classified "Always/Often/Sometimes" responders into the label user group and "Rarely/Never" responders into the label nonuser group.

Since the NLEA was enforced starting May 1994, we consider the 1991 and 1993 waves of NHIS to be pre-NLEA data, and the 1995 and 1998 waves to be post-NLEA. Compared with previous studies such as Moorman (1996), the four NHIS samples provide a broader span of time around NLEA's implementation to assess its impact. The 1993 and 1995 samples provide data immediately prior to and following the NLEA and the 1991 and 1998 samples provide data more separated from the event. Our main empirical estimates are derived from pooled data with an indicator for pre-NLEA and post-NLEA periods. Unlike previous studies, the large sample size provided by the NHIS enables us to conduct analysis by race/gender subgroups. This is particularly important since weight outcomes have a significant genetic component and cultural/gender factors exert a strong influence on weight-related behaviors (Cawley, 2004). 
In addition to the five categories of frequency of label use ("Always" to "Never"), respondents were given a sixth option of "Don't buy food." Those who don't buy food are neither in the treatment nor control group and so we exclude them from our main models. (After discussion of our primary results, we explain how our results change if we include these individuals in our sample.)

Table 1 reports the proportions of the population who report reading labels when buying food. Estimates for pre- and post-NLEA periods as well as 1991 and 1998 are presented, both for the overall adult population and broken down by race/gender groups. Overall label use is steady over the pre- and post NLEA periods at $67 \%$, although there is slight increase of 0.7 percentagepoints going from 1991 to 1998. In the way of comparison, using a similar label use definition as ours, FDA's Health and Diet Survey registered 70\% label use in 1994 and 69\% in 1995 and 2002 (FDA, 2004). In short, the NLEA does not seem to have altered the percent of people who use labels.

The proportion of those who report that they don't buy food rises from $4 \%$ in 1991 to $8.5 \%$ in 1998. A greater proportion of men than women report not buying food. For example, in the post-NLEA period, $11.8 \%$ of white men report not buying food compared to $2.1 \%$ of white women. In absolute terms, the increase in not buying food is mainly among men, although the proportion of women not buying food also increased from 1991 to 1998 . One reason for the increase in the proportion of those who don't buy food could be an increase in the number of individuals almost exclusively dining out. 


\section{Body Weight and Obesity}

We used Body Mass Index or BMI (ratio of weight in kilograms to the square of height in meters) as our primary outcome measure for estimating the impact of the new label on body weight. BMI was calculated from self-reported height and weight. In 1998 NHIS, all respondents personally reported their height and weight. In the NHIS for 1991, 1993, and 1995, height and weight were provided mostly by respondents, but in some cases proxy reports were used. NHIS provides a flag for proxy-reported height and weight and we excluded all such cases from our analysis. Since the onset of the health effects of excess body weight are especially linked to when a person is obese, we used an indicator for obesity status, defined as BMI $\geq 30$, as an additional outcome measure.

Table 2 reports the mean BMI and percentage obese estimated for different population groups. In general, both the mean BMI and the prevalence of obesity have increased over the pre- and post-NLEA period. Obesity is highest at around 30\% among black women. Although white women have the lowest obesity, they recorded a higher rate of increase both in the pooled and yearly pre- and post-NLEA data compared with black women.

\section{Other Covariates}

The goal of our empirical analysis is to estimate NLEA's impact by comparing the change in body weight of label users over the pre/post-NLEA period with the change in body weight of label nonusers over the same period. NHIS respondents are not randomized into the treatment group (label users) or control group (label nonusers); they self-select into these groups.

Therefore, label users and nonusers are likely to have different characteristics, and it is important 
to control for these differences. Previous research suggests that income, education, age, gender, household size and urban residence have significant influence on label use behavior (Kim, Nayga, and Capps, 2000; Neuhouser, Kristal, and Patterson, 1999). Table 3 lists these, as well as several additional sociodemographic and health characteristics that are included as controls in our models. There are some notable differences between the pre- and post-NLEA samples, which confirms the need to control for these variables in our empirical models. Distribution of family income has shifted lower in the post-NLEA period. The NHIS provides only a categorical income measure. The original measure has a significant number of missing values. NHIS data files include separate family income files which replace the missing values with imputed incomes. We used these income measures in our analysis. For 1998, family income was imputed using a multiple imputation procedure. We took this into account using SUDAAN's multiple imputation option.

In 1993 and 1995, the supplementary questionnaires containing the label use questions were administered to only half the sample of adults. In 1995, these adults were distributed evenly throughout the year. However, in 1993, the half sample consisted of adults interviewed in the second half of the year. This is reflected in the higher proportion individuals in the $3^{\text {rd }}$ and $4^{\text {th }}$ quarters in the pre-NLEA sample (table 3). Any seasonality introduced by this is taken into account by including quarter dummy variables in our models.

We included several covariates to account for possible differences and changes in health status, health behavior, and health attitudes. Health condition and health preferences were controlled by including self-assessed health status, number of days bedridden in the past 12 months, smoking 
status, and a variable indicating the frequency of adding salt to food at the table. Preferences for weight were proxied using indicators for individual's current action regarding his or her body weight (e.g. trying to lose weight, trying to gain weight, not doing anything).

\section{Results}

\section{Basic Results}

Table 4 reports estimates of the terms in equation 1, with the DD estimates of the NLEA effect, $\hat{\delta}$, presented in the final column. These estimates in Table 4 reflect models that do not control for sociodemographic or health characteristics (we will later present estimates from models that do control for those characteristics). The upper panel presents results based on BMI and the bottom panel gives results based on percent obese. Estimates were obtained for the overall population and for four major non-Hispanic race/gender subgroups. In all cases, label users had greater body weight compared with label nonusers in the pre-NLEA period. For example, the 1991-93 obesity prevalence in the population overall was $17.07 \%$ among label users and $14.51 \%$ among label nonusers. With the exception of white women, this pattern held in the post-NLEA period as well. This is likely because, at any given time, heavier persons may be using labels in their attempt to lose weight. For this reason, differences in weight status between label users and nonusers at any given time cannot be used to draw inference on the efficacy of the labels. What we are interested is in the change in weight status of label users and nonusers and the difference between these changes. These estimates are reported, respectively, in columns 3, 6, and 7 .

Column 3 estimates in table 4 show that in most cases, the body weight of label users increased significantly from the pre-NLEA period to the post-NLEA period. Thus, clearly the effect of the 
new labels hasn't been forceful enough to reverse the trend of rising obesity. However, besides label information, many other economic and social factors influence body weight. Changes in these factors could mask any potential label effect. Since these factors affect label nonusers as well, an estimate of their effect on body weight is given by the difference in weight of label nonusers across the pre- and post-NLEA periods. These estimates reported in column 6 show that, with the exception of black men, body weights of label nonusers also increased significantly from the pre-NLEA to the post-NLEA period. Column 7 reports the DD label effect, that is, the change in weight of label users relative to that of label nonusers. With non-label effects removed, the body weight of the overall population of label users actually fell in the post-NLEA period, as measured both by the mean BMI and by percent obese. However, breakdown of the label effect by race/gender groups reveals great disparity. The largest beneficial label effect on body weight is for non-Hispanic white women. With the introduction of the new labels, there was a net reduction of $0.52 \mathrm{~kg} / \mathrm{m}^{2}$ in their BMI and a 3.36 percentage-points reduction in obesity. Obesity declined among black women as well, by nearly 5 percentage points, although the decline in their BMI wasn't statistically significant. New labels had no effect on the body weight of white men. For black men, we get a seemingly anomalous result: introduction of new labels actually increased their body weight. However, before reading too much into these results, we have to account for the possibility that the results could be due to selection bias-difference in sociodemographic characteristics between label users and nonusers. To control for such differences, we adopt the regression framework in equation 2 .

\section{Regression Results}


Table 5 presents label effects estimated from DD regressions with BMI as the dependent variable. We estimated two regression models, one with a limited covariate specification that included only the sociodemographic characteristics and a second one with a full covariate specification that included the sociodemographic characteristics plus the health characteristics. These health characteristics are endogenous. For example, some individuals may smoke because smoking acts as an appetite suppressant and thus help them to reduce their weight. Those reported to be in excellent health may be so because of lower body weight. And those trying to lose weight are likely to do so because they perceive themselves to be overweight. However, these variables are also likely to capture individuals' preference for health and attitudes toward body weight that may affect their current weight and change in weight over time. Therefore, we estimated a separate model with these health variables included.

In both the limited and full models, characteristics were allowed to have period-specific effects on BMI through interactions between the pre/post-NLEA indicator and the covariates. Both models were estimated for the overall population and by non-Hispanic race/gender groups. For brevity, only the estimated label effects - that is, the coefficient of the $L A B E L_{i}{ }^{*} N L E A_{i}$ interaction, $\delta_{l}$-are reported.

The results are fairly clear. Non-Hispanic white women benefited from the new food labels introduced by the NLEA. Based on the estimate from the full covariate specification, their BMI on average is $0.3 \mathrm{~kg} / \mathrm{m}^{2}$ lower than it would have been without the new labels. The label effect is insignificantly different from zero for the rest of the race/gender groups and for the overall population, under the full covariate specification. For black men, the anomalous increase in 
weight is observed - but only in the limited covariate specification. With health variables included under the full covariate specification, the magnitude of the label effect for black men is reduced nearly by half and the estimate is statistically insignificant.

The inclusion of health variables in the model adds considerable explanatory power to the BMI regressions; in some cases the $\mathrm{R}^{2} \mathrm{~s}$ triple. The effects of covariates are along the expected lines (estimates not reported here but are available from the authors). Based on the regression estimate for the overall population, ceteris paribus, smokers have significantly lower BMI than non-smokers. Those reported to be in excellent or very good health have, on average, $1.5 \mathrm{~kg} / \mathrm{m}^{2}$ lower BMI compared with those in fair or poor health. Those who are trying to lose weight have $3.5 \mathrm{~kg} / \mathrm{m}^{2}$ higher BMI and those who are trying to gain weight have $3.7 \mathrm{~kg} / \mathrm{m}^{2}$ lower BMI compared with those who are trying to stay the same or not doing anything about their weight. All the included sociodemographic variables have significant correlations with the BMI. BMI is positively related to age and negatively to family income and individual's education level.

Table 6 reports DD estimates of the label effect with a person's obesity status as the dependent variable. We report results from a linear probability model (with coefficients converted to percentage points by multiplying by 100). Results from logistic regressions were similar. The obesity regressions lead to the same conclusions as the BMI regressions: Non-Hispanic white women benefited from the introduction of the new labels. Based on the full covariate specification, obesity prevalence among white women is 2.36 percentage-points lower than it would have been without the new labels. The labels have a statistically insignificant effect on obesity prevalence among the other race/gender groups and for the population overall. Once 
again, labels seem to be associated with an increase in obesity among black men, but this effect is insignificant in the full model.

Both the basic and regression results discussed so far were from samples that excluded adults who responded "Don't buy food" to the label use question. We reestimated the BMI and obesity regressions models reported in tables 5 and 6 with these individuals included in the label nonuser category. The results were similar, with a consistent beneficial effect found for non-Hispanic white women. The results were very stable under the limited covariate specification-label effect on BMI was -0.4 for white women, the same as in table 5 . In the full covariate specification, the estimates were slightly lower and less precise. This instability is surprising given that among white women, those who don't buy food constitute a very small fraction, 2.1\% in the post-NLEA period. This suggests that non-food-buyers are a special group that should be excluded from the comparison group as was done for models reported in tables 5 and 6 .

\section{Effects Across Different Periods}

A key assumption in interpreting the DD regression results is that the label effects estimated across the pre-/post-NLEA periods are due to the enforcement of mandatory labeling in 1994 and not due to an underlying trend in weight change that already existed before the introduction of the new labels. With two years of pre-NLEA data (1991 and 1993) and two years of post-NLEA data (1995 and 1998), we can test this assumption. Table 7 reports DD label effects for nonHispanic white women estimated across different time periods. The key results appear in the first row. This row gives the change in BMI and obesity due to label use from 1991 to 1993. The unadjusted results are positive and significant while the covariate-adjusted effects are also 
positive but not significantly different from zero. This suggests that there was no pre-existing trend in the weights of white women label users compared with white women label nonusers. If anything, the underlying trend for label users relative to label nonusers in the pre-NLEA was of weight gain rather than weight loss. This trend reversed sharply in the post-NLEA period, as the rest of the results in table 7 show. Between 1993 and 1995, the label effect resulted in a reduction of $0.45 \mathrm{~kg} / \mathrm{m}^{2}$ of BMI among non-Hispanic white women. Comparing 1993 with 1998, obesity fell by 3.2 percentage points.

\section{Effects Across BMI Distribution}

The results with obesity as the dependent variable show that label effects for non-Hispanic white women occur at parts of the BMI distribution that matter most for health outcomes - those who are heaviest. To illustrate this more clearly, we estimated the basic DD label effects at various points along the BMI distribution. Table 8 reports these results, which are not adjusted for covariates. The label effect at the median, $-0.5 \mathrm{BMI}$ units, is essentially the same as at the mean $(-0.52)$ reported in Table 4. The label effects, however, are larger at the upper end of the BMI distribution than at the lower end, as the estimates charted in Figure 1 clearly show. These results confirm that the benefits of the label are concentrated among non-Hispanic white women of higher body weights.

\section{Monetary Impact of the NLEA}

Prior to the implementation of the NLEA, the FDA had estimated the health benefits from the new labels to be between $\$ 4.4$ and $\$ 26.5$, realized over 20 years (Food and Drug Administration, 1993). This estimate can be put in perspective given our finding of a beneficial effect of the 
label for non-Hispanic white women. We translate our estimate of the average reduction in BMI of white women due to the new label into dollar terms using four sources of potential benefits from the BMI reduction: lower mortality risk, lower medical expenditures, reduced absenteeism, and increased productivity. ${ }^{3}$ Estimates of the implied marginal benefit from these sources associated with a reduction in one unit of BMI are obtained from published sources. We then assess the per-person value of the benefit attributable to the new label using our preferred estimate of the BMI reduction of 0.3 due to the NLEA (table 5). For each source, this estimate is then multiplied by the number of non-Hispanic white female label users to get the total benefit attributable to the new label from that source. The number of non-Hispanic white women label users is estimated by multiplying the census estimate of white women in 1994 (the year of NLEA implementation) by 0.75 , the average fraction of white women label users in our data. Finally, the benefits from all four sources are summed to obtain the total benefits from the NLEA.

Table 9 reports our monetary benefit estimates. The estimate for the reduction in mortality risk associated with lower BMI is from Calle et. al. (1999). They report age-adjusted death rates for white females at different BMI ranges. Based on overweight prevalence estimates reported by Flegal et al. (1998) using the 1988-94 NHANES data, we assume that the median non-Hispanic white female BMI in 1994 to be in the 23.5-24.9 range. From Calle et al., the implied marginal reduction in death risk for a 1-unit decline in BMI for white women from this range to the next lower category is 0.0133 percentage points. Using FDA's (Zarkin et. al., 1993) estimate of the value of statistical life in 1988 dollars ( $\$ 1.5$ million), the 0.3-unit BMI decline resulting from the NLEA has a monetary benefit of $\$ 60$ per white female label user. ${ }^{4}$ Across all white female label users, this implies that the reduction in mortality associated with the NLEA is worth $\$ 4.4$ billion 
per year. In its final regulatory impact analysis for the NLEA, FDA reported the value of health benefits gained over a twenty-year period, in 1991 dollars, using a 5-percent discount rate. In the final column of table 9, we report comparable figures for each source of health benefits. The estimated value of benefits from mortality risk reduction associated with label use among nonHispanic white women over 20 years is $\$ 63$ billion.

Similar calculations for benefits from the decrease in BMI associated with the NLEA imply benefits of about $\$ 23$ billion from reduced medical expenditure (based on estimates for females from Finkelstein, Fiebelkorn, and Wang, 2003), \$ 8 billion from lower absenteeism (based on estimates for females Finkelstein, Fiebelkorn, and Wang, 2005), and \$71 billion from increased productivity (based on estimates for white females from Cawley, 2004). ${ }^{5}$ Including mortality, the total benefits from the NLEA gained over a 20-year period is $\$ 166$ billion (in 1991 dollars), which is far higher than the upper limit of both the costs ( $\$ 2.3$ billion) and the benefits ( $\$ 26.5$ billion) projected by the FDA. If mortality benefits are excluded, the benefits over 20 -years are $\$ 102$ billion. Based our estimates, therefore, the costs of the NLEA are far exceeded by the benefits associated with the reduction in the body weight of non-Hispanic white women.

\section{Discussion}

The Nutrition Labeling and Education Act (NLEA), enacted in 1990 and enforced since 1994, represented the first comprehensive overhaul of U.S. food labeling laws in 50 years. By providing access to consistent, standardized, and credible nutrition information, the law was expected to help consumers choose more healthful foods and thereby promote better health outcomes. FDA estimated the value of health benefits from new labels to be between $\$ 4.4$ and 
\$26.5 billion, realized over 20 years. The total cost of NLEA implementation, including administrative and compliance costs, was projected to be between $\$ 1.4$ billion and $\$ 2.3$ billion.

To date, there has been little evaluation of NLEA impact dietary and health outcomes among Americans. Using a unique set of pre- and post-NLEA data on the label use habits of U.S. adults, this paper examined whether mandatory labeling introduced by the NLEA had an impact on body weight. The findings indicate that the NLEA labels had a beneficial impact, but only for one demographic group — non-Hispanic white females. As a result of the new labels introduced by the NLEA, the BMI and probability of obesity among white female label users were significantly lower than they would have been in the absence of the new labels. The total monetary benefit due to lower mortality, reduced medical expenditures, declining absenteeism, and increased productivity associated with this reduction in body weight was estimated to be about $\$ 166$ billion (1991 dollars) over a 20-year period.

Our estimates have significant implications for nutrition labeling initiatives in the U.S. and at the international level. One important implication is that label benefits may be limited to certain demographic groups. Future research should investigate why most groups in the U.S. do not seem to benefit (at least in terms of body weight) from these regulations. A second implication is that our assessment of the benefits of the mandatory labeling initiative in the U.S. may offer guidance for similar initiatives being considered by other countries.

Our study has some limitations. First, it is based on non-experimental data. If our controls (which include time-varying effects of education, income, marital status, health, health 
behaviors, and dieting attempts) do not adequately capture how self-selection among label users may have changed over time, our estimates could be biased. However, examining the stability of our results against two sources of such bias - the changing effects of unobservables using their observable correlates and testing for the existence of an underlying trend in the body weight of label users and nonusers in years prior to NLEA—suggests that any bias is likely to be small. Second, there may be additional benefits due to dietary changes associated with the increased supply of healthier foods from industry reformulation of foods following the NLEA. Such benefits are not taken into account in this study. Third, any improvements in consumer welfare due to substitutions among foods that may result from the release of new nutrition information following NLEA's implementation are also not considered in this study. 


\section{Footnotes}

1. For a timeline of food labeling laws in the United States and events leading up to the NLEA, see Kurtzweil (1993).

2. There is a more extensive literature on the determinants of label use, on the effect of nutrition labels that predate the NLEA on dietary outcomes, and on NLEA's impact on the food manufacturing industry. See Porter and Earl (1990), Teisl and Levy (1997), and Variyam (2005) for examples.

3. FDA's benefits estimates were based on the number of life-years gained due to dietary changes triggered by the new label. Specifically, the benefits were assumed to result from lower intakes of total fat, saturated fat, and cholesterol and the associated reduction in the risk of coronary heart disease and cancer (Zarkin et al., 1993). Therefore, our result for benefits from the reduction in mortality risk is the one most comparable to FDA estimates.

4. Since overweight and obesity likely increased between 1988 and 1994, the assumption of median BMI in the 23.5-24.9 range for non-Hispanic white women in 1994 is conservative. If median BMI in the 25.0-26.4 is assumed, the per-person value of the implied marginal reduction in mortality risk increases to $\$ 162$.

5. For medical expenditure and absenteeism, the implied marginal benefits are derived from a shift from the obese to the overweight category. For productivity, Cawley (2004) provides an estimate of the rise in wages that would result from a 1-unit reduction in BMI for white females. We interpret the wage as the marginal revenue product of labor, and therefore as a measure of productivity. 


\section{References}

Balasubramanian, S.K., and C. Cole. “Consumers' Search and Use of Nutrition Information: The Challenge and Promise of the Nutrition Labeling and Education Act." Journal of Marketing 66 (July 2002): 112-127.

Bitler, M., J.B. Gelbach, and H.W. Hoynes. "Welfare Reform and Health" (June 2004). NBER Working Paper No. W10549.

Calle, Eugenia E., Michael J. Thun, Jennifer M. Petrelli, Carmen Rodriguez, and Clark W. Heath. "Body-Mass Index and Mortality in a Prospective Cohort of U.S. Adults." New England Journal of Medicine, 341(15) (1999): 1097-1105.

Cawley, John. "The Impact of Obesity on Wages." Journal of Human Resources, Spring 2004, 39(2): 451-474.

Finkelstein, E.A., I. C. Fiebelkorn, and G. Wang. "National medical spending attributable to overweight and obesity: How much, and who's paying?” Health Affairs 2003;W3;219-226.

Finkelstein, E.A., I. C. Fiebelkorn, and G. Wang. "The Costs of Obesity Among Full-time Employees." American Journal of Health Promotion 20 (2005): 45-51.

Finkelstein, A. "The effect of tax subsidies to employer-provided supplementary health insurance: evidence from Canada." Journal of Public Economics 84 (2002): 305-339.

Flegal, K.M, M.D. Carroll, R.J. Kuczmarski, and C.L. Johnson. "Overweight and obesity in the United States: prevalence and trends, 1960-1994." International Journal of Obesity 22 (1998): $39-47$.

Flegal K, Carroll M, Ogden C, Johnson C. "Prevalence and Trends in Obesity Among US Adults, 1999-2000.” Journal of the American Medical Association 288 (2002): 1723-1727.

Food and Drug Administration. Counting Calories: Report of the Working Group on Obesity. March 2004. http://www.cfsan.fda.gov/ dms/owg-toc.html.

Food and Drug Administration. "Regulatory Impact Analysis of the Final Rules to Amend the Food Labeling Regulations.” Federal Register, Vol. 50, No. 3, January 1993.

Food and Drug Administration. The Food Label. May 1999. http://www.fda.gov/opacom/backgrounders/foodlabel/newlabel.html.

Foulke, J. "Nutrition Information on Restaurant Menus." FDA Talk Paper. Food and Drug Administration. U.S. Department of Health and Human Services. July 30, 1996.

www.vm.cfsan.fda.gov/ /rd/tpmenus.html. 
Hawkes, C. Nutrition Labels and Health Claims: The Global Regulatory Environment. World Health Organization, 2004. http://whqlibdoc.who.int/publications/2004/9241591714.pdf

Institute of Medicine. Dietary Reference Intakes: Guiding Principles for Nutrition Labeling and Fortification. Washington, DC: National Academy Press, 2003.

Kim, S-Y., R. M. Nayga, Jr., and O. Capps, Jr. "The Effect of Food Label Use on Nutrient Intakes: An Endogenous Switching Regression Analysis." Journal of Agricultural and Resource Economics 25(July 2000): 215-231.

Kreuter, M.W., and L.K. Brennan, Scharff, D. P., and S. N. Lukwago. "Do Nutrition Label Readers Eat Healthier Diets? Behavioral Correlates of Adults' Use of Food Labels." American Journal of Preventive Medicine 13(1997): 277-283.

Kristal, A.R., L. Levy, R.E. Patterson, M. Neuhouser, M.L. Neuhouser. "Predictors of selfinitiated, healthful dietary change." Journal of the American Dietetic Association 101 (2001): 762-766.

Kurtzweil, P. "New Food Label: Good Reading for Good Eating.” FDA Consumer 27(May 1993).

Kurtzweil, P. “Making It Easier to Shed Pounds.” FDA Consumer 28(July-Aug. 1994).

Moorman, C. "A Quasi Experiment to Assess the Consumer and Informational Determinants of Nutrition Information Processing Activities: The Case of the Nutrition Labeling and Education Act.” Journal of Public Policy and Marketing 15(Spring 1996): 28-44.

National Center for Health Statistics. Data File Documentation, National Health Interview Survey, 1998 (machine readable data file and documentation). National Center for Health Statistics, Centers for Disease Control and Prevention, Hyattsville, Maryland. Available at http://www.cdc.gov/nchs/nhis.htm. 2000.

Neuhouser, M. L., A. R. Kristal, and R. E. Patterson. "Use of food nutrition labels is associated with lower fat intake." Journal of the American Dietetic Association 99(January 1999): 45-53.

Pappalardo, J. K. "Evaluating the NLEA: Where's the Beef?” Journal of Public Policy \& Marketing 15:1(2001): 153-156.

Perez-Escamilla, R. and L. Haldeman. "Food label use modifies association of income with dietary quality." Journal of Nutrition 132 (2002): 768-772.

Philipson, T. Government perspective: food labeling. The American Journal of Clinical Nutrition 82: 1(S), July 2005: 262S-264S.

Porter, D. V., and R. O. Earl (Eds). Nutrition Labeling: Issues and Directions for the 1990s. National Academy Press, Washington, D.C., 1990. 
Research Triangle Institute. SUDAAN 9. User's Manual. Research Triangle Park, NC, 2005.

Teisl, M.F., and A.S. Levy. "Does Nutrition Labeling Lead to Healthier Eating?" Journal of Food Distribution Research 28(October 1997): 18-27.

Variyam, J. N. Nutrition Labeling in the Food-Away-From-Home Sector: An Economic Assessment. Economic Research Report No. 4, Economic Research Service, USDA, Washington, DC, 2005. http://www.ers.usda.gov/publications/ERR4/

Zarkin, G.A., N. Dean, J.A. Mauskopf, and R. Williams. "Potential Health Benefits of Nutrition Label Changes." American Journal of Public Health 83 (May 1993): 717-724. 
Table 1. Nutrition Label Use in pre- and post-NLEA periods, 1991-98 NHIS

\begin{tabular}{|c|c|c|c|c|}
\hline Population & $1991-93$ & $1995-98$ & 1991 & 1998 \\
\hline \multicolumn{5}{|l|}{ Overall } \\
\hline Excluding "Don’t Buy Food" & 67.0 & 67.1 & 66.1 & 66.8 \\
\hline Including "Don’t Buy Food" & 64.7 & 62.5 & 63.4 & 61.1 \\
\hline Don’t Buy Food & 3.4 & 6.8 & 4.0 & 8.5 \\
\hline \multicolumn{5}{|l|}{ Non-Hispanic White Men } \\
\hline Excluding "Don’t Buy Food" & 57.8 & 58.8 & 57.3 & 58.8 \\
\hline Including "Don't Buy Food" & 54.0 & 51.9 & 52.9 & 50.5 \\
\hline Don’t Buy Food & 6.6 & 11.8 & 7.6 & 14.1 \\
\hline \multicolumn{5}{|l|}{ Non-Hispanic Black Men } \\
\hline Excluding "Don’t Buy Food" & 58.3 & 57.7 & 58.8 & 59.9 \\
\hline Including "Don’t Buy Food" & 54.1 & 49.7 & 53.9 & 49.5 \\
\hline Don't Buy Food & 7.3 & 13.8 & 8.3 & 17.4 \\
\hline \multicolumn{5}{|l|}{ Non-Hispanic White Women } \\
\hline Excluding "Don't Buy Food" & 75.2 & 76.8 & 73.8 & 76.7 \\
\hline Including "Don't Buy Food" & 74.3 & 75.2 & 72.7 & 74.9 \\
\hline Don't Buy Food & 1.3 & 2.1 & 1.5 & 2.4 \\
\hline \multicolumn{5}{|l|}{ Non-Hispanic Black Women } \\
\hline Excluding "Don’t Buy Food" & 70.4 & 68.5 & 69.1 & 69.5 \\
\hline Including "Don't Buy Food" & 69.6 & 66.4 & 68.0 & 67.0 \\
\hline Don’t Buy Food & 1.1 & 3.1 & 1.6 & 3.6 \\
\hline
\end{tabular}


Table 2. Body Mass Index and Obesity in pre- and post-NLEA periods, 1991-98 NHIS

\begin{tabular}{lcccc}
\hline Population & $1991-93$ & $1995-98$ & 1991 & 1998 \\
\hline & \multicolumn{5}{c}{ BMI $\left(\mathrm{kg} / \mathrm{m}^{2}\right)$} \\
Overall & 25.5 & 26.2 & 25.4 & 26.3 \\
Non-Hispanic White Men & 26.1 & 26.6 & 25.9 & 26.7 \\
Non-Hispanic Black Men & 26.5 & 27.3 & 26.3 & 27.6 \\
Non-Hispanic White Women & 24.8 & 25.4 & 24.6 & 25.5 \\
Non-Hispanic Black Women & 27.6 & 28.1 & 27.4 & 28.2 \\
& & & & \\
& 16.1 & 19.1 & 15.3 & 20.0 \\
Overall & 14.9 & 18.1 & 14.1 & 19.1 \\
Non-Hispanic White Men & 18.1 & 22.9 & 16.0 & 25.7 \\
Non-Hispanic Black Men & 14.8 & 17.6 & 14.3 & 18.0 \\
Non-Hispanic White Women & 30.9 & 30.3 & 29.3 & 32.1 \\
Non-Hispanic Black Women & & & & \\
\hline
\end{tabular}


Table 3. Variables and sample means

\begin{tabular}{|c|c|c|}
\hline Variable & $1991-93$ & $1995-98$ \\
\hline Age $18-24$ & 10.5 & 11.0 \\
\hline Age 25-34 & 22.6 & 21.0 \\
\hline Age $35-44$ & 21.4 & 22.4 \\
\hline Age 45-64 & 26.5 & 28.5 \\
\hline Age $65+$ & 19.0 & 17.1 \\
\hline Male & 39.4 & 42.6 \\
\hline Female & 60.6 & 57.4 \\
\hline Non-Hispanic White & 77.0 & 75.5 \\
\hline Non-Hispanic Black & 11.2 & 11.0 \\
\hline Non-Hispanic Other & 3.9 & 4.1 \\
\hline Hispanic & 8.0 & 9.5 \\
\hline Married & 61.5 & 59.9 \\
\hline Widowed & 9.3 & 7.8 \\
\hline Divorced/Separated & 12.3 & 11.7 \\
\hline Never Married & 17.0 & 20.6 \\
\hline Family income $<\$ 5,000$ & 0.8 & 2.3 \\
\hline Family income $\$ 5,000$ - $\$ 9,999$ & 1.9 & 4.2 \\
\hline Family income $\$ 10,000-\$ 14,999$ & 2.5 & 4.9 \\
\hline Family income $\$ 15,000$ - $\$ 19,999$ & 2.4 & 4.7 \\
\hline Family income $\$ 20,000-\$ 24,999$ & 9.8 & 8.5 \\
\hline Family income $\$ 25,000$ - $\$ 34,999$ & 16.1 & 14.8 \\
\hline Family income $\$ 35,000$ - $\$ 44,999$ & 12.1 & 11.6 \\
\hline Family income $>\$ 49,999$ & 54.5 & 48.9 \\
\hline Family size & $\begin{array}{c}2.6 \\
(0.01)\end{array}$ & $\begin{array}{l}2.7 \\
(0.01)\end{array}$ \\
\hline Less than High School $(<12 \mathrm{yrs})$ & 20.0 & 17.7 \\
\hline High School (=12 yrs) & 37.0 & 32.4 \\
\hline Some College (13-15 yrs) & 22.1 & 26.4 \\
\hline College (16+yrs) & 20.8 & 23.5 \\
\hline MSA & 78.1 & 79.2 \\
\hline Non-MSA & 21.9 & 20.8 \\
\hline Northeast & 20.5 & 19.4 \\
\hline Midwest & 24.6 & 24.7 \\
\hline
\end{tabular}


Table 3. Variables and sample means

\begin{tabular}{lcc}
\hline Variable & $1991-93$ & $1995-98$ \\
\hline & 32.8 & 34.0 \\
Weuth & 22.1 & 19.9 \\
& 11.6 & 25.0 \\
Quarter 1 & 12.3 & 24.6 \\
Quarter 2 & 38.1 & 25.3 \\
Quarter 3 & 37.9 & 25.0 \\
Quarter 4 & 67.0 & 67.1 \\
& 33.0 & 32.9 \\
Read nutrition label always/often/sometimes & \\
Read nutrition label rarely/never & 25.6 & 24.1 \\
& 74.4 & 75.9 \\
Smoker & & \\
Nonsmoker & 61.0 & 63.2 \\
& 25.7 & 24.9 \\
Excellent/Very Good Health & 13.3 & 11.9 \\
Good Health & & \\
Fair/Poor Health & 33.2 & 33.6 \\
& 3.5 & 3.5 \\
Trying to Lose Weight & 63.3 & 62.9 \\
Trying to gain Weight & & \\
Stay the same/not doing anything & 6.1 & 5.0 \\
& $(0.2)$ & $(0.2)$ \\
No. of bed days in past 12 months & 22.9 & 22.3 \\
& 20.9 & 23.1 \\
Always/often add salt to food at the table & 56.1 & 54.6 \\
Sometimes add salt to food at the table & & \\
Rarely/Never add salt to food at the table & 64,760 & \\
Sample size (N ) & & \\
& & \\
\hline
\end{tabular}


Table 4. Mean BMI and Percent Obese by Label Use Status and the Estimated Difference-inDifferences Label Use Effect, 1991-93 / 1995-98

\begin{tabular}{|c|c|c|c|c|c|c|c|}
\hline \multirow[t]{2}{*}{ Population } & \multicolumn{2}{|c|}{ Label User } & \multicolumn{4}{|c|}{ Label Non-User } & \multirow[b]{2}{*}{$\hat{\delta}=\Delta_{\mathrm{u}}-\Delta_{\mathrm{n}}$} \\
\hline & $1995-98$ & $1991-93$ & $\Delta_{\mathrm{u}}$ & $1995-98$ & 1991-93 & $\Delta_{\mathrm{n}}$ & \\
\hline \multicolumn{8}{|c|}{ BMI $\left(\mathrm{kg} / \mathrm{m}^{2}\right)$} \\
\hline Overall & 26.26 & 25.67 & $0.59 * * *$ & 26.03 & 25.22 & $0.81 * * *$ & $-0.22 * *$ \\
\hline \multicolumn{8}{|l|}{ Non-Hispanic } \\
\hline White men & 26.93 & 26.39 & $0.54 * * *$ & 26.28 & 25.73 & $0.55 * * *$ & 0.01 \\
\hline Black men & 27.94 & 26.71 & $1.23 * * *$ & 26.61 & 26.17 & 0.43 & $0.79 *$ \\
\hline White women & 25.44 & 24.92 & $0.52 * * *$ & 25.36 & 24.32 & $1.04 * * *$ & $-0.52 * * *$ \\
\hline Black women & 28.53 & 28.13 & $0.40 * *$ & 27.32 & 26.47 & $0.86 * *$ & -0.45 \\
\hline \multicolumn{8}{|c|}{ Obesity (Percent) } \\
\hline Overall & 19.69 & 17.07 & $2.62 * * *$ & 18.40 & 14.51 & $3.89 * * *$ & $-1.27^{*}$ \\
\hline \multicolumn{8}{|l|}{ Non-Hispanic } \\
\hline White Men & 19.57 & 15.89 & $3.68 * * *$ & 16.52 & 13.89 & $2.64 * * *$ & 1.04 \\
\hline Black Men & 26.60 & 18.92 & $7.67 * * *$ & 18.92 & 18.18 & 0.74 & $6.93 * *$ \\
\hline White Women & 17.29 & 15.18 & $2.11 * * *$ & 18.75 & 13.28 & $5.47 * * *$ & $-3.36 * * *$ \\
\hline Black Women & 34.02 & 34.16 & -0.14 & 28.16 & 23.32 & $4.84 * *$ & $-4.98^{*}$ \\
\hline
\end{tabular}

$* * *=\mathrm{p}<0.01, * *=\mathrm{p}<0.05$, and $*=\mathrm{p}<0.10$ 
Table 5. Estimated Label Use Effect from Difference-in-Differences Regressions for BMI

\begin{tabular}{|c|c|c|c|c|c|}
\hline \multirow[t]{3}{*}{ Population } & \multicolumn{4}{|c|}{$1991-93$ / 1995-98 } & \\
\hline & \multicolumn{2}{|c|}{$(1)$} & \multirow{2}{*}{\multicolumn{2}{|c|}{$\begin{array}{ll} & (2) \\
\hat{\delta} & \mathrm{R}^{2}\end{array}$}} & \\
\hline & $\hat{\delta}$ & $\mathrm{R}^{2}$ & & & \\
\hline Overall & $\begin{array}{l}-0.09 \\
(0.93)\end{array}$ & 0.08 & $\begin{array}{c}-0.02 \\
(.24)\end{array}$ & 0.23 & 85,753 \\
\hline \multicolumn{6}{|l|}{ Non-Hispanic } \\
\hline White Men & $\begin{array}{c}0.06 \\
(0.45)\end{array}$ & 0.06 & $\begin{array}{c}0.16 \\
(1.23)\end{array}$ & 0.22 & 24,186 \\
\hline Black Men & $\begin{array}{l}0.83^{* *} \\
(2.04)\end{array}$ & 0.06 & $\begin{array}{c}0.46 \\
(1.25)\end{array}$ & 0.30 & 3,647 \\
\hline White Women & $\begin{array}{l}-0.40^{* *} \\
(2.47)\end{array}$ & 0.06 & $\begin{array}{l}-0.30 * * \\
(1.99)\end{array}$ & 0.21 & 38,224 \\
\hline Black Women & $\begin{array}{l}-0.31 \\
(0.81)\end{array}$ & 0.07 & $\begin{array}{l}-0.20 \\
(0.56)\end{array}$ & 0.24 & 7,615 \\
\hline $\begin{array}{l}\text { Sociodemographic } \\
\text { Variables included }\end{array}$ & \multicolumn{2}{|l|}{ Yes } & \multicolumn{3}{|c|}{ Yes } \\
\hline $\begin{array}{l}\text { Health Variables } \\
\text { Included }\end{array}$ & \multicolumn{2}{|l|}{ No } & \multicolumn{3}{|c|}{ Yes } \\
\hline $\begin{array}{l}\text { Interactions of Included } \\
\text { Variables and pre-/post } \\
\text { NLEA indicator }\end{array}$ & \multicolumn{2}{|c|}{ Yes } & \multicolumn{3}{|c|}{ Yes } \\
\hline
\end{tabular}

Absolute t-ratios are in parentheses; $* * *=p<0.01, * *=p<0.05$, and $*=p<0.10$. Here, and in all regressions, sociodemographic variables included are age, marital status, income, education, family size, MSA, region, and interview quarter. The health variables included are smoking, self-assessed health status, current effort to lose/gain weight, number of days bedridden in the past 12 months, and use of table salt. See Table 1 for definition of these variables. 
Table 6. Estimated Label Use Effect from Difference-in-Differences Regressions for Obesity

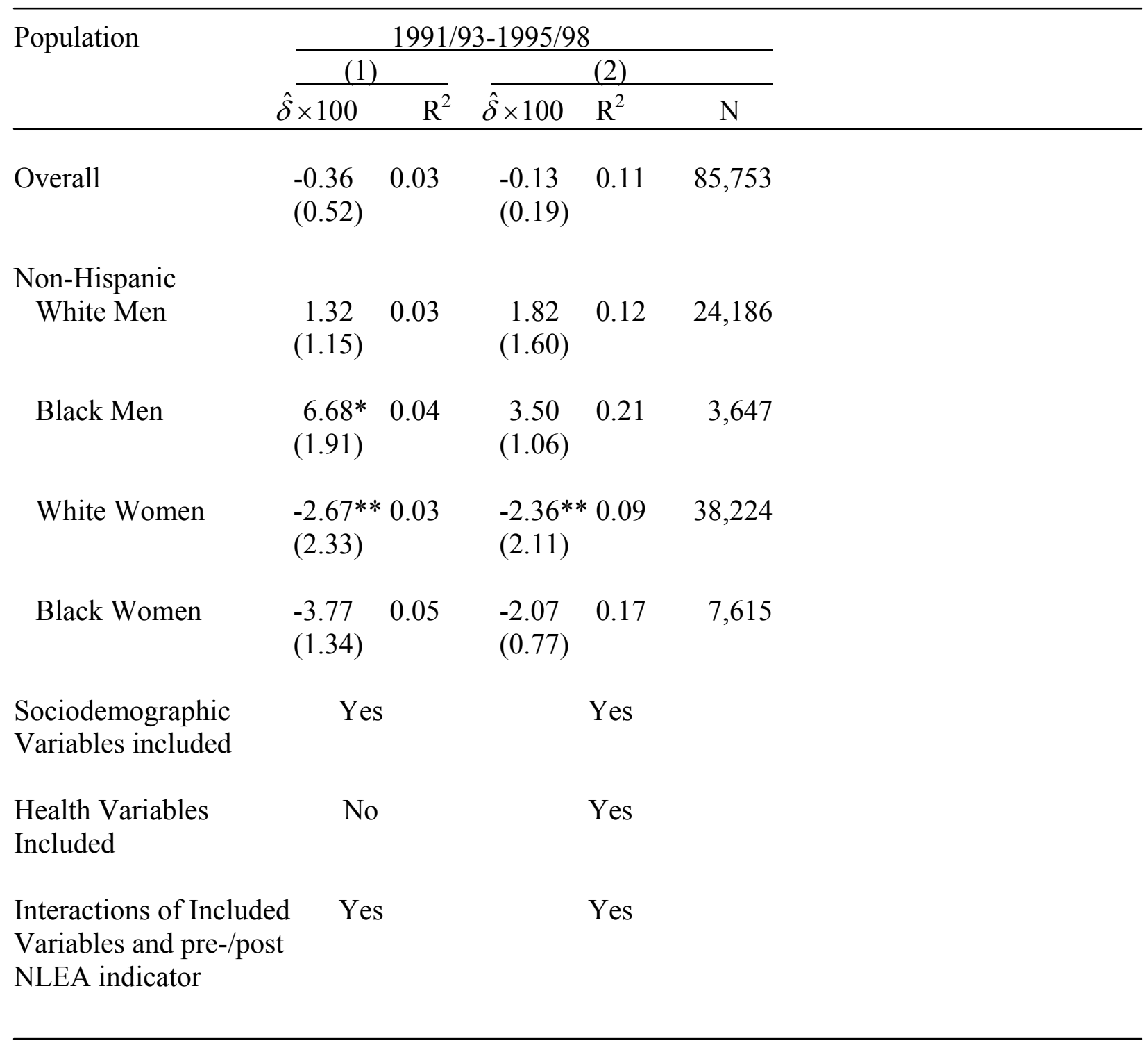

Absolute t-ratios are in parentheses; ${ }^{* * *}=\mathrm{p}<0.01,{ }^{* *}=\mathrm{p}<0.05$, and ${ }^{*}=\mathrm{p}<0.10$. 
Table 7. Label Use Effects for Non-Hispanic White Women Estimated Across Various Time Periods

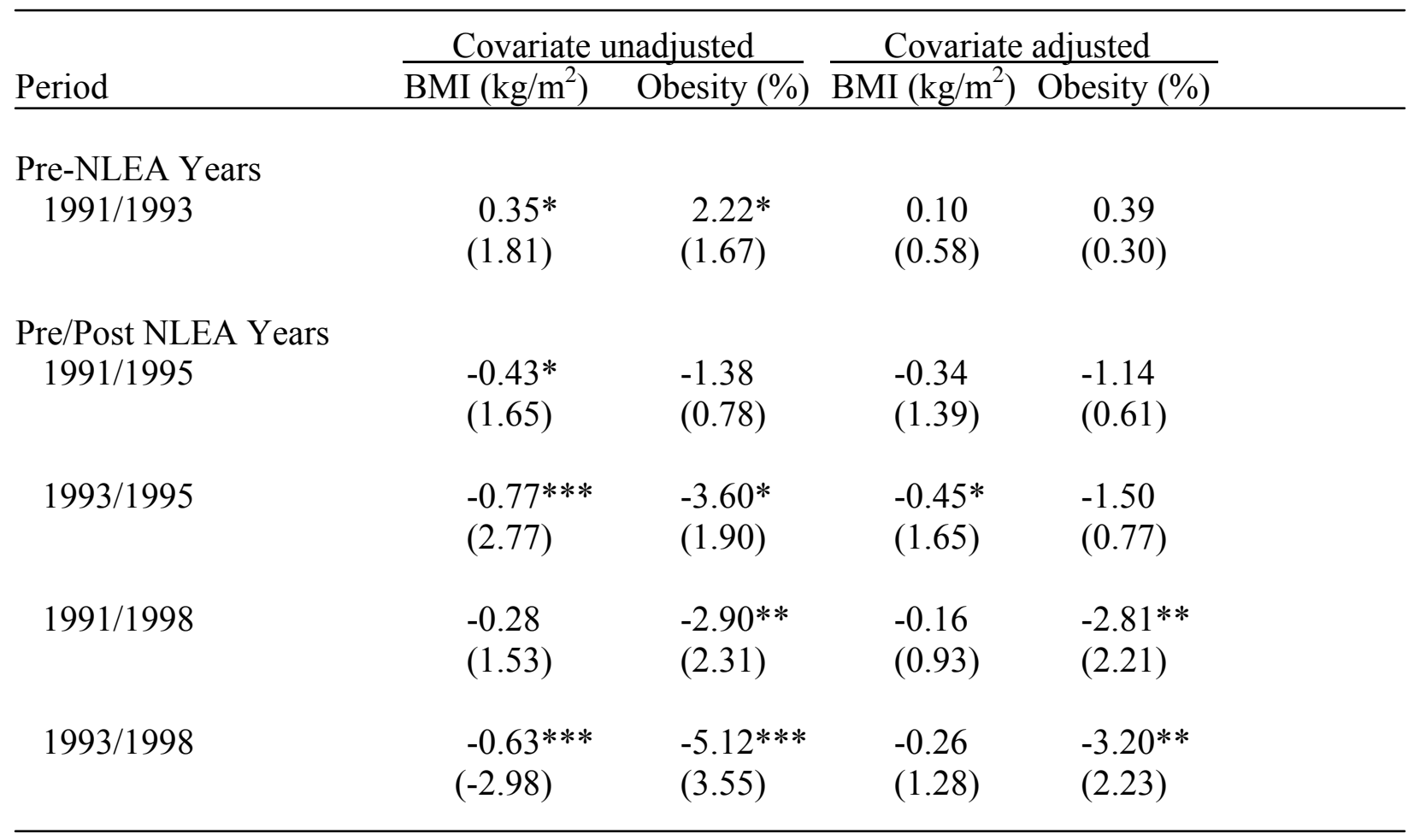

Absolute t-ratios are in parentheses; $* * *=\mathrm{p}<0.01, * *=\mathrm{p}<0.05$, and $*=\mathrm{p}<0.10$. 
Table 8. Differences and Difference-in-Differences in BMI Percentiles between1991/93 and 1995/98 by Label Use Status, for Non-Hispanic White Women

\begin{tabular}{lccccccc}
\hline Percentile & \multicolumn{2}{c}{ Label Users } & \multicolumn{5}{c}{ Label Non-User } \\
& $1995 / 98$ & $1991 / 93$ & $\Delta_{\mathrm{u}}$ & $1995 / 98$ & $1991 / 93$ & $\Delta_{\mathrm{n}}$ & $\delta=\Delta_{\mathrm{u}}-\Delta_{\mathrm{n}}$ \\
\hline 5 & 19.00 & 18.75 & 0.25 & 18.31 & 17.91 & 0.39 & -0.14 \\
15 & 20.56 & 20.19 & 0.37 & 20.09 & 19.53 & 0.56 & -0.19 \\
25 & 21.60 & 21.22 & 0.38 & 21.22 & 20.71 & 0.52 & -0.14 \\
35 & 22.61 & 22.21 & 0.40 & 22.46 & 21.66 & 0.80 & -0.40 \\
50 & 24.19 & 23.75 & 0.44 & 24.20 & 23.26 & 0.95 & -0.50 \\
65 & 26.47 & 25.72 & 0.75 & 26.55 & 24.99 & 1.56 & -0.82 \\
75 & 28.26 & 27.39 & 0.87 & 28.34 & 26.59 & 1.75 & -0.88 \\
85 & 30.68 & 29.93 & 0.74 & 31.07 & 29.17 & 1.90 & -1.15 \\
95 & 35.63 & 34.84 & 0.78 & 36.00 & 34.34 & 1.66 & -0.88 \\
& & & & & & & \\
\hline
\end{tabular}


Fig 1. Differences and Difference-in-Differences in BMI percentiles between pre- and postNLEA periods by label use status for non-Hispanic white women

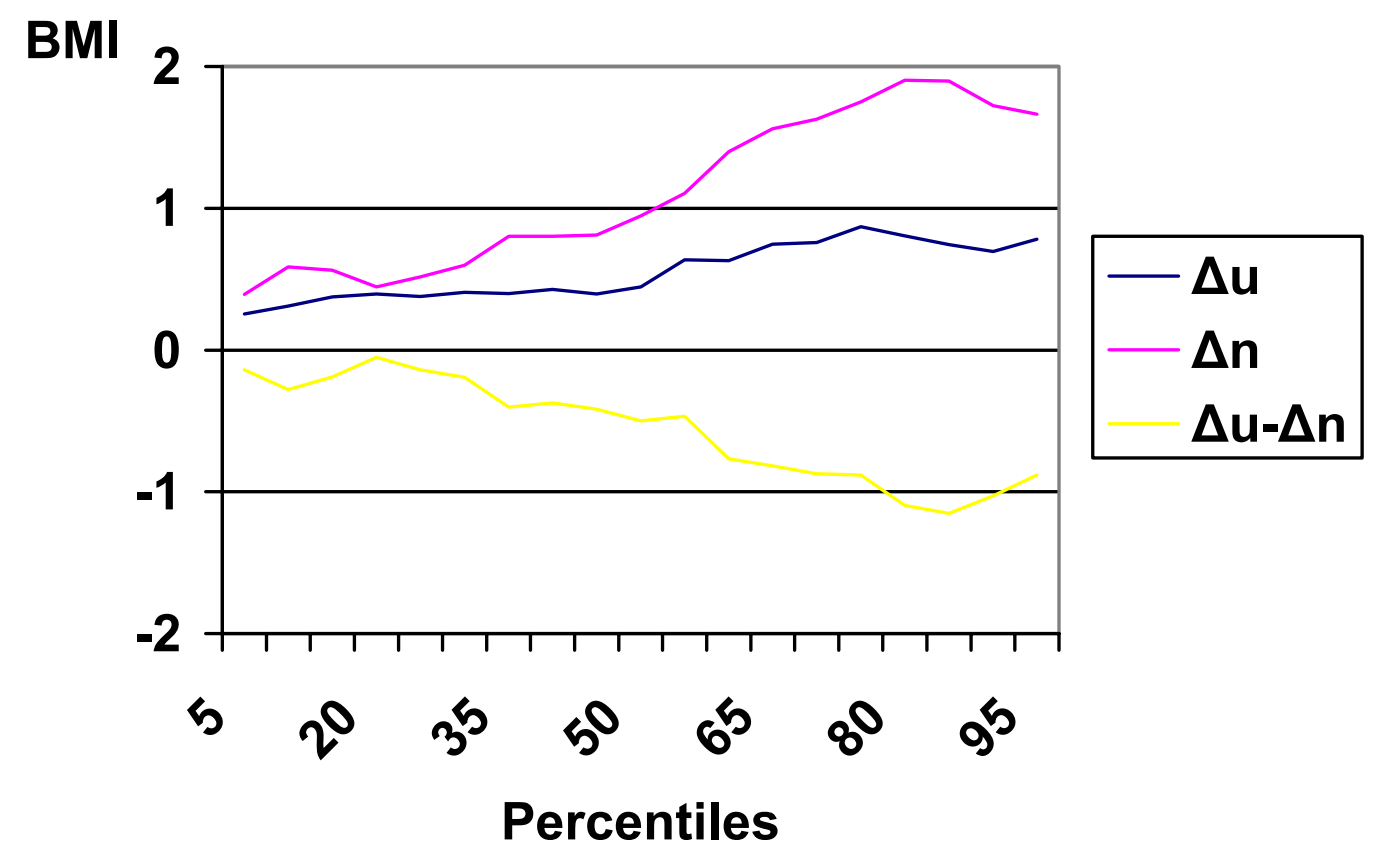


Table 9. Monetary Benefits from the NLEA

\begin{tabular}{lccc}
\hline Source & $\begin{array}{c}\text { Per-Person Value } \\
(\$)\end{array}$ & $\begin{array}{c}\text { Total Benefit } \\
\text { (Million 1988 \$) }\end{array}$ & $\begin{array}{c}\text { Benefits over 20 years }^{\mathrm{b}} \\
\text { (Million 1991 \$) }^{\mathrm{a}}\end{array}$ \\
\hline Mortality & 60 & 4,424 & 63,472 \\
Medical Expenditures & 35 & 1,596 & 22,896 \\
Absenteeism & 13 & 579 & 8,308 \\
Productivity & 74 & 4,962 & 71,199 \\
\hline Total (Excluding Mortality) & - & 7,137 & 102,402 \\
Grand Total & - & 11,561 & 165,875 \\
\hline
\end{tabular}

${ }^{a}$ Derived from published sources. Mortality value is based on marginal reduction in death risk due to lower BMI from Calle et. al. (1999). The value of a statistical life is taken as $\$ 1.5$ million (in 1988 \$) as in Zarkin et al. (1993). Benefits from reduced medical expenditures and absenteeism due to lower BMI are from Finkelstein, Fiebelkorn, and Wang $(2003,2005)$. Benefits from higher productivity is from Cawley (2004).

${ }^{\mathrm{b}}$ Discounted at 5 percent. The estimates are presented in 1988 and 1991 \$ for comparison with FDA's estimates reported in Zarkin et al. (1993) and Food and Drug Administration (1993). 